\title{
Deservingness Transfers
}

\author{
Knut Olav Skarsaune \\ Penultimate draft, forthcoming in Utilitas
}

This paper seeks to cause trouble for a brand of consequentialism known as "desertarianism". In somewhat different ways, views of this kind evaluate outcomes more favourably, other things equal, the better the fit between the welfare different people enjoy and the welfare they each deserve. These views imply that we can improve outcomes by redistributing welfare to fit desert, which seems plausible enough. Unfortunately, they also imply that we can improve outcomes by redistributing desert to fit welfare: in other words, by making happy people more deserving, at the cost of making unhappy people less deserving. Extant versions of desertarianism predict that such "deservingness transfers" are improvements and that we ought to carry them out. Even worse, they will sometimes rank deservingness transfers higher than simply benefitting deserving people who are poorly off.

Desertarianism is a form of consequentialism that includes considerations of desert in the evaluation of outcomes. It has significant intuitive appeal. Given a world where the wicked prosper and the virtuous suffer, and an otherwise similar world where the reverse is true, most people would say the latter is better.

I will present an objection to views of this kind. I describe a case where we can cause a happy but undeserving person to become more deserving, in a way that unavoidably will also cause a highly deserving but unhappy person to become less deserving. The contemplated act will, in other words, produce a "deservingness transfer". Desertarian views imply, implausibly, that this transfer will improve the outcome and that we ought to carry it out. Even worse, they will sometimes rank deservingness transfers higher than simply benefitting deserving people who are poorly off.

One desertarian, Richard Arneson, has anticipated a similar but weaker objection. His main reply hinges on the way in which the objection he anticipates is weaker, and will not help here. However, he also suggests another reply, namely to deny that it is possible to influence other people's deservingness, which would prevent the problem from arising to begin with. In response, I show that the price of this reply is that it needs a radical view of the desert base, the feature in virtue of which people become more or less deserving. It cannot include virtue, good or 
evil deeds, or even effort. It must, in other words, reject many of the intuitions that attract people to desertarianism in the first place.

\section{Desertarianism}

First some parameters for the discussion. This paper has a restricted and shamelessly negative aim: to press an objection against a group of consequentialist views, which I will describe in this section. I will not assess how other ethical theories that include some role for desert would fare against the objection, nor attempt any general discussion of the place of desert in moral theory.

The views I will discuss are defined by two features: $a$ ) they include considerations of desert (in ways I will shortly describe) in the evaluation of outcomes, and $b$ ) they say that right action is action that brings about the best available outcome (or one of the best, in case of ties). This kind of view is normally referred to as "desertarianism", but just to be extra clear, we can borrow a term from Parfit and call it "telic desertarianism". My target in this note is telic desertarianism, and nothing else.

I find this kind of view a worthy target because, were it not for the objection I will shortly present, I would find it rather plausible. If some version of this view could be made to work, it would seem to combine the theoretical attractions of consequentialism (that we ought never deliberately make the world worse than we might) with judgments about cases that are more in line with pre-theoretical intuitions than those of utilitarianism.

Like the views I will discuss, I will take welfare to be the "currency of desert", the thing one can deserve more or less of. It will not matter for our purposes whether we think of it as welfare-in-life-as-a-whole or welfare-at-a-time.

With the exception of Arneson (1999, 2007) and Hurka (2001), desertarians tend not to say much about the desert base, the feature that makes people more or less deserving. Instead, their focus has been to investigate what kind of structure the axiology should have. But they tend to think that virtue is at least a part of the desert base, and an unofficial convention seems to have developed, in giving examples and so on, to write as if the desert base is simply virtue, on the understanding that this is a stand-in for something potentially more complex. ${ }^{1}$ I will

\footnotetext{
${ }^{1}$ Hurka (2001) thinks virtue is the desert base, while Kagan thinks it is either the whole or a large part of it (2012: 6-7). Feldman includes virtue (2002: 623) and "moral worthiness" (1995: 574) in his list of likely desert bases. Skow (2012: 235-7), Valentyne (1995: 208-9) and Arrhenius (2007: 17) use virtue in their examples, but are officially agnostic about the desert base. Carlson (1997)
} 
follow that convention in this section and the next, and return to the issue of the desert base in section 3 .

There are two main kinds of telic desertarianism. The first treats people getting what they deserve as an intrinsic value, which makes an independent contribution to the value of outcomes. The other treats desert as a modifier, which affects the way welfare contributes to outcome value.

Defenders of the first kind of view include Shelly Kagan (2012), Thomas Hurka (2001), and, at least as a friendly commentator, Gustaf Arrhenius (2007). I will briefly present Kagan's view for purposes of illustration. Kagan actually defends two intrinsic values having to do with desert. The first, noncomparative desert, works as follows. To increasing levels of virtue, there correspond increasing amounts of welfare that people at those virtue levels deserve. If a person gets exactly the welfare she deserves, that has intrinsic value. If she gets more or less than she deserves, this value declines (eventually going negative) the further away (in either direction) she is from getting what she deserves. This intrinsic value is computed for each person individually, and added to or subtracted from the total value of the outcome, together with any other values, such as welfare, that we recognize.

(This last point is important. Suppose for example that a mildly virtuous person enjoys enormous welfare. This will have negative value, so far as noncomparative desert is concerned. But for Kagan, the welfare as such has independent value, making the overall situation positive).

The second value, comparative desert, is more complicated, having to do with the pattern of fit between welfare and virtue in a world. If everybody has exactly what they deserve, or they all overshoot or all undershoot in ways that "offend equally against noncomparative desert", ${ }^{2}$ comparative desert is satisfied. This has intrinsic value, which is added to the overall value of the outcome. The further away from this condition a world is, the less there is of this intrinsic value (it will often be negative).

Desert-as-modifier theorists include Fred Feldman (1995, 2002, 2006), Eric Carlson (1997), Richard Arneson (1999, 2007) and Bradford Skow (2012). ${ }^{3}$ Feldman's view is probably the best known, but Skow's has the advantage of being statable as an equation (Feldman's is expressed

criticises Feldman's axiology, and proposes an alternative, without dissenting about the desert base.

2 To spell out this condition would take many pages; see Kagan (2012: ch. 8).

${ }^{3}$ Peter Vallentyne (1995) also develops a desert-as-modifier view, without officially endorsing it. 
in prose, with illustrative graphs). It will therefore be convenient to use Skow's version for purposes of illustration, but the objection I will make applies equally to all these views.

Skow's view works as follows. The impartial value a person's welfare contributes to an outcome is a function of the welfare she deserves and the welfare she enjoys, given by this equation:

Impartial value $=$ Deserved welfare $\times \ln \left(\left(\frac{e}{2}\right)\left(1+\frac{\text { Actual welfare }}{\text { Deserved welfare }}\right)\right) \times k$

The details here are not important for our purposes. ${ }^{4}$ Consider instead this graph, to illustrate the substance of Skow's view:

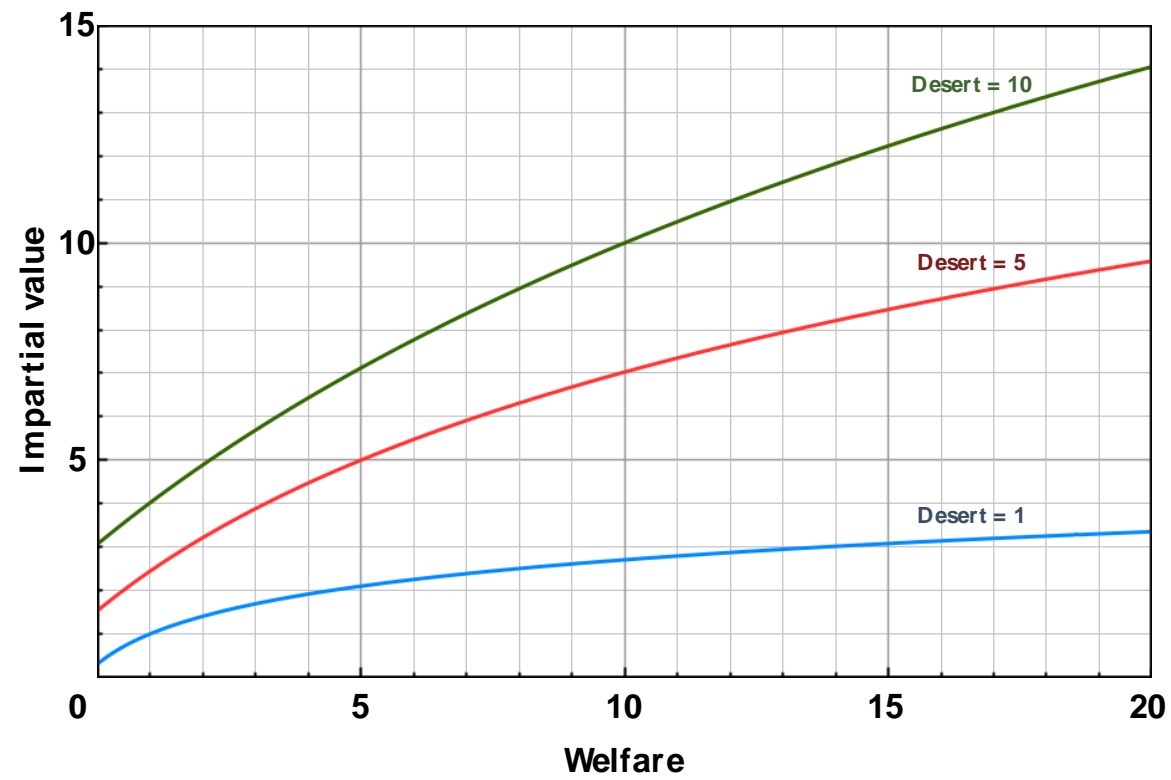

The impartial value of each person's welfare is calculated according to

${ }^{4} k$ is a constant used to make the equation "dimensionally consistent". On the left hand side we have impartial value (good), and on the right hand side we have welfare (good for). Since these are different quantities, it would be confused to assert an identity between some amount of impartial value and some amount of welfare. So we need to add a constant that "translates" between the two quantities. For example, if hedons are our measure of welfare and morons our measure of impartial value, then $k$ might be 1 moron/hedon or 9,81 morons/hedon. For simplicity, I have drawn the grap and calculated the tables below in a way that assumes the number in $k$ is 1 . Giving it some other value would make no substantive difference.

The purpose of $e$ (Euler's number) divided by 2 is to make the factor "In (...)" come out to 1 in the case where a person gets exactly what she deserves.

Skow's view is only meant to cover cases where both welfare and desert are positive. As one can see on the graph, the lines approach the y-axis above zero, suggesting that Skow's view also places some independent value on deservingness. But as we shall see in section 3, that makes no difference to the objection I will present. 
this function, and then added together to get the overall value of the outcome.

\section{Deservingness transfers}

Now for the objection. The consequentialist literature is full of debates about which welfare transfers would, and which would not, make outcomes better. But if outcome value is some function of the distributions of both welfare and desert, it follows that we can make outcomes better, not just by redistributing welfare, but also by redistributing desert. This has ungainly implications. Consider:

Happy Nasty and Unhappy Nice are stranded on a deserted island. We are unable to affect their welfare. We are, however, able to place a copy of Reasons and Persons in Happy Nasty's possession in a way that will unavoidably also put a copy of The Art of The Deal in Unhappy Nice's possession. ${ }^{5}$ If we do this, it will predictably lead Happy Nasty to become a bit more virtuous and Unhappy Nice to become a bit less virtuous.

On Kagan's view, this transfer will improve the situation in several ways. Since the virtue of each is brought closer to what it would need to be for them to deserve the welfare levels they are at, each of their noncomparative desert scores go up. And the comparative desert score of their island improves as well, for even though their welfare levels still "offend against noncomparative desert" in opposite directions, they now do so to lesser degrees. Since neither's welfare is affected, these are all net gains in outcome value.

To see how the example plays out on Skow's view, we can run the numbers for some illustrative values of welfare and desert:

\begin{tabular}{|c|c|c|c|c|c|}
\hline & \multicolumn{2}{|c|}{ Unhappy Nice } & \multicolumn{2}{c|}{ Happy Nasty } & \multirow{2}{*}{ Impartial value } \\
\cline { 2 - 5 } & welfare & desert & welfare & desert & \\
\hline \hline Status quo & $\mathbf{1}$ & $\mathbf{1 0}$ & $\mathbf{1 0}$ & $\mathbf{1}$ & $4,0+2,7=\mathbf{6 , 7}$ \\
\hline Deservingness transfer & $\mathbf{1}$ & $\mathbf{9}$ & $\mathbf{1 0}$ & $\mathbf{2}$ & $3,7+4,2=\mathbf{7 , 9}$ \\
\hline
\end{tabular}

The deservingness transfer improves the outcome considerably. The positive effect on how Happy Nasty's welfare is "discounted" (raising the impartial value of her 10 units of welfare from 2,7 to 4,2), is greater than the negative effect on the way Unhappy Nice's welfare is "marked up" (lowering the impartial value of her 1 unit of welfare from 4,0 to $3,7)$.

\footnotetext{
${ }^{5}$ Perhaps we can float them a map in a bottle showing where the books are buried, and we know that Happy Nasty will grab the book with the nicest cover picture.
} 
Even worse, Kagan and Skow's views imply that deservingness transfers can be better than benefitting deserving people with low welfare. Let us add a third option to the example above: suppose we can instead benefit Unhappy Nice a little, by floating her a first aid kit. So long as the benefit is small, Skow's view implies that this option is less good than the deservingness transfer:

\begin{tabular}{|c|c|c|c|c|c|}
\hline & \multicolumn{2}{|c|}{ Unhappy Nice } & \multicolumn{2}{|c|}{ Happy Nasty } & \multirow{2}{*}{ Impartial value } \\
\cline { 2 - 5 } & welfare & desert & welfare & desert & \\
\hline \hline Status quo & $\mathbf{1}$ & $\mathbf{1 0}$ & $\mathbf{1 0}$ & $\mathbf{1}$ & $4,0+2,7=\mathbf{6 , 7}$ \\
\hline Deservingness transfer & $\mathbf{1}$ & $\mathbf{9}$ & $\mathbf{1 0}$ & $\mathbf{2}$ & $3,7+4,2=\mathbf{7 , 9}$ \\
\hline Welfare boost & $\mathbf{2}$ & $\mathbf{1 0}$ & $\mathbf{1 0}$ & $\mathbf{1}$ & $4,9+2,7=\mathbf{7 , 6}$ \\
\hline
\end{tabular}

Kagan does not express his view numerically, or tell us how heavily desert weighs against other values. But so long as he puts any weight on desert (without which it would be irrelevant) his view will have implications of the same kind.

We can imagine real-world scenarios with the same structure. Consider a sharply divided society, with a rich class living high and a poor class scraping by. Suppose the political situation renders us powerless to do anything about this welfare distribution. We are, however, able to intervene (say, by making changes to the programming on state television) in a way that will, over time, cause the rich to become marginally more virtuous and the poor to become marginally less virtuous. Assuming, again, that this will have no net effect on the welfare levels of the two classes, Kagan and Skow's views predict that it will nevertheless make the outcome better and that we ought to carry it out, by the same logic that we have explored above.

All these results are morally implausible. Given a world where the virtuous suffer and the wicked prosper, it seems perverse to think that the right response can be to take away some of the virtuous's virtue and give it to the wicked. And it seems even more perverse that such interventions can be better than benefitting people who are both virtuous and poorly off.

That is the objection. Now some comments about its scope. I defined telic desertarianism as the combination of desertarian axiology, and act consequentialism. Which part does the objection target?

It targets their conjunction. An act consequentialist can of course avoid the objection by not having a desertarian axiology. A desertarian who wants to keep her axiology can avoid the objection by abandoning or qualifying her act consequentialism. For example, she could introduce a non-consequentialist constraint or reason against "deservingness sabotage", the intentional reduction of someone's deservingness. Then, she can say, even though the outcome where Happy Nasty is a bit less 
nasty, and Unhappy Nice a bit less nice, is better than the status quo, this constraint blocks us from acting to bring it about. ${ }^{6}$

But I doubt whether a desertarian could plausibly just add this constraint and otherwise leave the view as it was. The question is how stable the resulting view would be. Once we open the floodgates to nonconsequentialist reasons or constraints, why just that one? Why not one against, say, breaking promises? Why not theft and murder? But if we pile on constraints, we will gradually abandon the consequentialist attempt to explain right action, and end up with something that looks more like a Rossian plurality of duties, including - like Ross' view - a duty to promote the good.

Alternatively, she may try to ground a constraint against deservingness sabotage in some more general principle, perhaps against violating autonomy, or treating people as mere means. But that would of course take her straight to a much wider departure from consequentialism. Once we pick up such a principle, we cannot put it down again at will. If we shouldn't sabotage people's deservingness because that would violate their autonomy, then there are presumably lots of other optimific things we shouldn't do because they would violate people's autonomy.

As mentioned earlier, I find telic desertarianism interesting because, if it worked, it would seem able to combine the theoretical and explanatory virtues of consequentialism with verdicts about cases that are closer to common sense than those of utilitarianism. For the reasons just given, it seems difficult for a desertarian to respond to the transfer problem by just adding a constraint against deservingness sabotage, without a wider sacrifice to the first of these motivations.

A different response, which would retain both motivations, would be to try to enrich the axiology. Instead of a constraint against deservingness sabotage, a desertarian could count it as an intrinsic evil, a bad thing, to be included when we evaluate outcomes. Of course, the examples also include the opposite intervention, which we might call "deservingness assistance". But if she introduced a suitable asymmetry, either not counting deservingness assistance as intrinsically good, or less good than sabotage is bad, she could presumably arrange the overall axiology in such a way that it does not count deservingness transfers as net improvements.

Unfortunately, this modified view is vulnerable to a modified form of the objection (which also gets around any constraints against deservingness sabotage). There are cases that exhibit a similar logic to the examples above, without requiring sabotage of anyone's

\footnotetext{
${ }^{6}$ Thanks to an anonymous reviewer for pressing me to clarify this.
} 
deservingness, but simply assisting them less than others. Some people have a sunny disposition, being naturally disposed to enjoy life in a wide range of circumstances. Others are gloomier by default, not disposed to stay happy for long even in fortunate circumstances. If we assume that happiness is at least one component of welfare, even the modified view would imply, ceteris paribus, that other people (including parents and teachers) should allocate their deservingnessassisting efforts more towards those with a sunny than those with a gloomy disposition. That way, those who are going to have more welfare anyway will also be more deserving, at the cost of leaving those who are going to have less welfare anyway less deserving. Such a policy seems morally implausible in much the same way as the original result.

Returning to the question of the scope of the main objection, does it target all telic desertarian views? For concreteness, I have shown how deservingness transfers produce unpleasant implications for one desertas-intrinsic-value view and one desert-as-modifier view. The objection generalizes along one dimension but not along another. It can be avoided if we are willing to make some very strong claims about the desert base, a point I will return to. But so long as virtue, or some other feature that can be affected by other people's actions, is part of the desert base, I cannot see how any of the desertarian views in the literature would avoid the objection. Despite subtle differences in axiology, these views all imply that outcomes are better when their welfare distributions fit their desert distributions. Therefore, we can make outcomes better by improving the fit between welfare and deservingness. But so far as the axiology is concerned, it makes no difference whether we do this by redistributing welfare to fit desert, or by redistributing desert to fit welfare.

Despite the differing shapes of their axiologies, then, the objection generalizes to telic desertarian views that include virtue in the desert base, among them Kagan, Feldman and Hurka's, and apparently also Arrhenius, Carlson and Skow's. ${ }^{7}$

\section{The desert base}

Richard Arneson, however, may possess a means of escape. In Desert and Equality (2007), he anticipates an objection that is similar but, as we will see, importantly weaker:

Suppose that we can by action now affect the extent to which people, ourselves or others, are deserving in the future. Then if

\footnotetext{
${ }^{7}$ See footnote 1.
} 
morality requires, inter alia, that one bring it about that people achieve good fortune proportionate to their desert, it will sometimes be right to bring it about that a well-being gain should go to a (now) less deserving rather than to a more deserving person, just because this (as it seems) deliberate maldistribution will bring it about that those who are now more deserving will become less deserving. Maybe the mistreated will become inappropriately resentful or envious. This apparent implication of my view is weird and counterintuitive. (2007: $285)^{8}$

Arneson has two replies. The first is to suggest that he may not face this problem in the first place, because his account of the desert base may render it impossible for one person to affect another's deservingness. Call this the impossibility reply. He does not pursue this branch of the argument very far, however, and leaves it open whether this reply will work in the end (2007: 286).

Arneson's second reply takes up the other branch of the argument, i.e. what to say if it is possible to influence others' deservingness. What he says here hinges on a difference between our objection and the one he anticipates, namely that the latter involves reducing someone's deservingness without increasing anyone else's. This allows him to reply that his view will not recommend making people less deserving, even when that would improve the fit between welfare and desert, because it is intrinsically valuable that people are more deserving. He develops this claim further by embracing a "prioritarianism of desert", which says that desert has decreasing marginal value. In other words, an incremental unit of deservingness has more impartial value if it goes to a sinner than if it goes to a saint (2007: 286-288).

But appealing to the intrinsic value of deservingness will not help against deservingness transfers, which do not involve any net loss of deservingness. (This is why my argument in section 2 focused on transfers rather than uncompensated deservingness reductions.) And a prioritarianism of desert will in many cases even make the problem worse. For example, in the case of Happy Nasty and Unhappy Nice, we could transfer desert from the more deserving to the less deserving. Arneson's prioritarianism of desert would only make this transfer more attractive, perhaps making it better than simply giving Unhappy Nice two extra units of welfare.

With or without the prioritarianism of desert, then, we can conclude that

${ }^{8}$ Arneson credits Ingmar Persson for bringing the objection to his attention (Arneson 2007: 284, n. 18). Gustaf Arrhenius (2007: 18) discusses a similar objection. 
for Arneson to escape our objection, he needs the impossibility reply. This returns us to the question, which turns out to be crucial for the prospects of telic desertarianism, of what the desert base is, and whether it is possible to transfer it.

Let us say that the desert base is "insulated" if it is impossible to influence other people's deservingness, making deservingness transfers impossible. What kind of view can we take of the desert base, if we want it to be insulated? We cannot include virtue, since it is clearly possible to influence other people's virtuousness, say by raising children well or neglecting them. Nor can right action or evil deeds in themselves count, as the same example illustrates. Even effort, if understood in the usual way, cannot be included, since one can at least to some degree socialize people into habits of exertion or sluggishness.

Arneson's own account is a good example of the kind of view we must try if we want to insulate the desert base. As a first pass, he takes the desert base to be conscientiousness: "the degree to which they are steadily disposed to pursue what they believe to be right and good, provided that they have made good-faith efforts to discover what is genuinely right and good and are not culpable for embracing false beliefs" (2007: 272). But he recognizes that an agent's conscientiousness, in this sense, is shaped by nature and nurture like any other part of her psychology. To correct for this, he says that the desert base is not strictly an agent's conscientiousness, but the contribution made to her level of conscientiousness by her uncaused free will (2007: 275-7). ${ }^{9}$

Causa sui free will is of course a hefty metaphysical commitment. But let us simply take note of that without trying to assess its plausibility. Let us instead look at some normative implications of the account. A very distinctive part is that it concerns how people strive for what they believe to be good and right, where this should be read de dicto:

the deserving [person's] will is decisively oriented toward a blank check: she aims to do whatever it is that is morally right,

\footnotetext{
${ }^{9}$ I should add that Arneson elsewhere is open to a compatibilist account of free will (2004: 10-11, 1999: 239, 2007: 273, n. 11). If I read him correctly, his overall view is best understood as a series of conditionals: if libertarian free will exists, he will understand the desert base as described in this section, and give the impossibility reply. If some kind of compatibilism is true, he will grant that it is possible to influence others' deservingness, and instead give the "prioritarianism of desert" reply (2007: 286). And if hard determinism is true, he will abandon desertarianism and be a plain egalitarian/prioritarian (2004: 9).

Since we are here exploring the impossibility reply, I take the liberty of ascribing to Arneson the assumptions that go with that reply.
} 
and she tries to fill in the content of this aim by thinking through as best she can where the balance of moral reasons points [...] (2007: 277)

As Arneson admits, this implies that a conscientious Nazi will be highly deserving, given that conscientious Nazis are possible, i.e. that it is possible to be socialized into a good faith belief in Nazi morals (2007: 273). Another unpleasant implication concerns what we might call unreflective saints. It seems possible to be superbly morally good without having any explicit moral beliefs. Consider for example a Forrest Gump-like character, who is spontaneously kind and generous, without a thought in his head about right and wrong. Arneson's account does not give him any points for this.

A recurring theme in Arneson's writings on desert is the need to distinguish between intrinsic deservingness and instrumental considerations. Social norms that dole out blame and punishment to conscientious Nazis, and praise and reward to Forrest Gumps, are of course immensely useful, by incentivizing pro-social behaviour. It is not surprising that these norms have a strong grip on common sense intuitions (1999: 240-1, 2007: 267-8).

But let us try to correct for that. Suppose Forrest Gump and the conscientious Nazi have been permanently stranded on two deserted islands. We can ship a hammock and a mosquito net to one of them. Arneson's view implies that the conscientious Nazi deserves it more and should get it, other things equal.

My purpose has not been to refute Arneson's view, but simply to bring out some of its radical implications. There are of course other views one might try, in order to insulate the desert base. We come into contact here with the literature on moral responsibility. That literature is massive, and it would be madness to try to settle any deep questions here. Let me instead end by flagging a crucial difference that should not get lost in translation between that literature and the debate over desertarianism.

The central notions in the responsibility literature are moral praise- and blameworthiness. It is an open question whether deservingness, as it figures in desertarian theory, is the same thing. Thus, even if a given view should be plausible as an account of praise/blameworthiness, it does not follow that we can plug it into a desertarian theory, as an account of deservingness, without loss of plausibility.

For example, there are accounts of responsibility that seek something at least in the direction of insulation: when assigning credit for good or bad actions, they adjust for how difficult it was for the agent to act well 
or avoid acting badly. The guiding principle is that people are responsible for how they play the cards they are dealt, but not for their starting hand. Thus, if the conscientious Nazi is the way she is because she has been raised in a Nazi family, we adjust for the fact that this makes it extremely difficult for her to act well. Her blameworthiness might be small. Conversely, if Gump has simply been handed a saintly nature, making it easy for him to act well, we adjust for that. His praiseworthiness might be small.

An important resource for defenders of views of this kind is to introduce distinctions between different kinds of moral evaluation. For example, following Watson (1996), they can distinguish between "accountability blame" (expressed in indignation and resentment) and "attributability blame" (moral admiration or disdain, expressed in terms such as brave, lousy, virtous, etc). Thus, to defend her view's witholding of one kind of negative response to the conscientious Nazi (accountability blame), the theorist can soften the blow by offering us another kind of negative response instead (attributability blame/disdain). And to defend the witholding of accountability-praise from Forrest Gump, she can soften the blow by offering attributability-praise (admiration) instead (Nelkin 2016: 368).

When deciding on a desert base for the purposes of a desertarian normative theory, however, we cannot do this kind of double scorekeeping. Virtue is either included in the desert base, or it isn't. We can count good and evil deeds in full, or adjust in some way for difficulty, but we cannot do both. And it seems a very different task to defend the view that Forrest Gump isn't highly deserving of welfare, than to defend the view that he is attribuatbility-praiseworthy rather than accountability-praiseworthy.

There are significant challenges, then, if we want to insulate the desert base. We need, first, some distinction between "the cards one is dealt" and "how one plays them", which renders it impossible for others to influence how someone plays their cards. It is not clear whether such a distinction can be drawn without invoking libertarian free will. And we have to make plausible, second, that it is how someone in the relevant sense "plays their cards", and nothing else, that decides their deservingness. Without a view of that sort about the desert base, we get the problem of deservingness transfers.

\section{Conclusion}

We have considered a fairly simple objection. Telic desertarianism says that outcomes are better, ceteris paribus, when their welfare distributions fit their desert distributions, and that we should act to bring 
about such outcomes. The objection is that these views are blind to the moral difference between achieving such outcomes by giving people what they deserve, and by making them such as to deserve what they have got.

The objection applies to the most common form of desertarianism, which combines the view that virtue and/or good behaviour is at least a part of the desert base, with the telic assumption that the right place to locate considerations of desert in moral theory is in the value of outcomes. Three solutions suggest themselves: to develop a non-telic form of desertarianism; to develop an account of the desert base that insulates it from outside influence; or to abandon desertarianism altogether. ${ }^{10}$

\section{References}

Arneson, Richard. 1999. 'Egalitarianism and Responsibility', The Journal of Ethics, 3: 225-47

- - 2004. 'Luck Egalitarianism Interpreted and Defended', Philosophical Topics, 32: 1-20

- - 2007. 'Desert and Equality' in Egalitarianism: New essays on the nature and value of equality, ed. by Holtug, N., and Lippert-Rasmussen, K. (Oxford: Oxford University Press)

Arrhenius, Gustaf. 2007. 'Meritarian Axiologies and Distributive Justice' in Hommage à Wlodek. Philosophical Papers Dedicated to Wlodek Rabinowitcz, ed. by Rønnow-Rasmussen, T., Petersson, B., Josefsson, J., and Egonsson, D. (available online (as of 8. March 2018) at www.fil.lu.se/hommageawlodek)

Carlson, Erik. 1997. 'Consequentialism, Distribution and Desert', Utilitas, 9: 309-18

Feldman, Fred. 1995. 'Adjusting Utility for Justice: A Consequentialist Reply to the Objection from Justice', Philosophy and Phenomenological Research, 55: 567-85

- - 2002. 'The Good Life: A Defense of Attitudinal Hedonism', Philosophy and Phenomenological Research, 56: 604-28

- - 2006. Pleasure and The Good Life (Oxford: Oxford University Press)

Hurka, Thomas. 2001. 'The Common Structure of Virtue and Desert', Ethics, 112: 6-31

Kagan, Shelly. 2012. The Geometry of Desert (Oxford: Oxford University Press)

Nelkin, Dana Kay. 2016. 'Difficulty and Degrees of Moral Praiseworthiness

${ }^{10}$ Many thanks to Andreas Carlsson, Lars Christie, Finnur Dellsén, Kåre Letrud, Anders Nes and two anonymous reviewers for helpful comments. Work on this paper was supported by grant no. 240069 from the Norwegian Research Council. 
and Blameworthiness', Nous, 50: 356-78

Skow, Bradford. 2012. 'How to Adjust Utility for Desert', Australasian Journal of Philosophy, 90: 235-57

Vallentyne, Peter. 1995. 'Taking Justice Too Seriously', Utilitas, 7: 207-16

Watson, Gary. 1996. 'Two Faces of Responsibility', Philosophical Topics, 24: $227-48$ 